\title{
VERTICAL PLANE MOTION OF HIGH SPEED PLANING VESSELS WITH CONTROLLABLE TRANSOM FLAPS: MODELING AND CONTROL
}

\author{
Handa $\mathrm{Xi}^{*}$ and Jing Sun ${ }^{* *, 1}$ \\ * Dept. of Mechanical Engineering, \\ ** Dept. of Naval Architecture and Marine Engineering, \\ University of Michigan, Ann Arbor, MI 48109, USA
}

\begin{abstract}
Hydrodynamics of porpoising instability in vertical-plane motions of high-speed planing vessels have been investigated for years. However, not much work has been published on dynamic control of vertical-plane motions of planing boats by controllable appendages. In this paper, effects of controllable transom flaps on heave/pitch motion characteristics of high-speed planing vessels are investigated. A control-oriented nonlinear model is derived first for the high-speed prismatic planing craft equipped with a controllable transom flap in the calm water. Then, effects of different static flap deflections on the ship's equilibrium running attitude and vertical-plane motion stability are analyzed. Analysis shows that porpoising cannot be avoided at high speeds by presetting static transom flap deflections through static feedforward control. An LQR feedback controller is designed to achieve local asymptotical stability. Copyright (c)2005 IFAC
\end{abstract}

Keywords: High-speed planing vessels, vertical-plane motion, porpoising, modeling, LQR

\section{INTRODUCTION}

High-speed planing vessels exhibit many different dynamic instability phenomena in motions of both vertical and transverse planes, such as porpoising, chine walking, progressive heeling, unstable pitching-induced rolling, or a combination of them (Blount and Codega, 1992; Iketa and Katayama, 2000). Among these, porpoising might be the most well-known instability problem of high-speed planing crafts. It refers to the periodic, coupled heave/pitch oscillation in the vertical plane, which is sustained by the energy derived from the planing craft's forward speed and the planing lift force.

\footnotetext{
1 Corresponding author. jingsun@engin.umich.edu; Ph.: (734)-615-8061; Fax: (734)-936-8820
}

Starting from the early twentieth century, research on vertical-plane motions of high-speed planing vessels produced fruitful results during 60's-90's (Savitsky, 1964; Martin, 1978a,b; Troesch, 1992; Troesch and Falzarano, 1993; Hicks et al., 1995). These works focused mainly on the fundamentals of the planing boat dynamics and the effects of design parameters of the planing hull on its motion performance, such as porpoising. The design parameters studied included the location of center of gravity, load, forward speed and other geometric parameters of the vessel.

Meanwhile, appendages have been adopted to control vertical-plane motions of high-speed vessels, such as comfort ride improvement for a fast ferry by controllable transom flaps and T-foils (De la Cruz et al., 2004). As for planing boats, Savitsky 
and Brown (1976) gave empirical methods to determine hydrodynamic forces induced by a static transom flap and its effects on running trim, drag, power requirements and motion stability of the planing craft. However, compared to the considerable research progress made on hydrodynamics and design of planing boats, there has been little work published on model development and system analysis and design for vertical-plane motion control of planing vessels by controllable appendages.

This paper focuses on modeling of vertical-plane motions of high-speed planing vessels controlled by a transom flap, and investigates effects of flap deflections on the motion characteristics, including porpoising. A control-oriented nonlinear model is developed first for the prismatic highspeed planing vessel in the calm water equipped with a controllable transom flap, based on the combination of experimental hydrodynamic results and Savitsky's empirical method. Effects of different static transom flap deflections on the ship's equilibrium running attitude and verticalplane motion stability are investigated. Although the preset static deflection of the transom flap alters the motion response of the planing boat, porpoising cannot be eliminated by static flap deflections at high speeds. Our analysis even shows that large static transom flap deflections may induce porpoising at a lower forward speed. A Linear Quadratic Regulator (LQR) feedback controller is then adopted to achieve local asymptotical stability of high-speed planing vessels. The enhancement of stability by transom flaps will not only extend the safety speed range of the planing boat, but also mitigate the design constraints imposed on the vessel body.

This paper is organized as follows: In Section 2, a control-oriented nonlinear model is derived for the prismatic high-speed planing vessel with a controllable transom flap. Effects of the static deflection of the transom flap on craft's motion characteristics are analyzed in Section 3. In Section 4, an LQR controller is designed to maintain the boat's stability at high speeds. Finally, conclusions are given in Section 5 .

\section{A MODEL FOR PLANING VESSELS WITH CONTROLLABLE TRANSOM FLAPS}

The model described in this section combines fundamental physical laws and empirical relations. It provides the necessary tool for system analysis and controller design using model-based methodologies.

\section{Coordinate System and Motion Equation}

A right-handed coordinate system is defined in Fig.1 for the prismatic planing vessel running

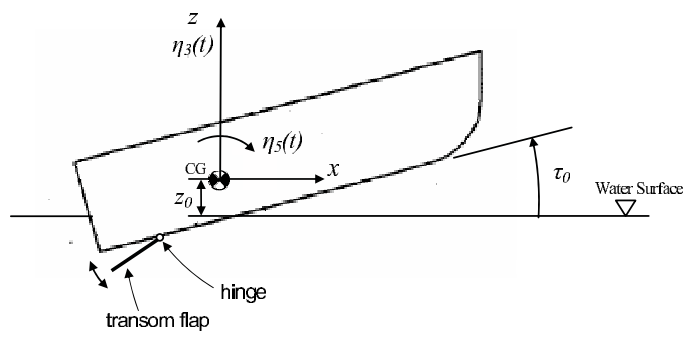

Fig. 1. Coordinate system of the planing vessel

in the calm water. At the equilibrium running attitude, the trim angle is defined as $\tau_{0}$, and the vertical distance of center of gravity (CG) from the water level as $z_{0} . \eta_{3}(t)$ and $\eta_{5}(t)$ are the vertical displacement (i.e., heave) of CG and the rotation (i.e., pitch) of the vessel relative to the inertia axis, respectively. $\eta_{3}(t)$ is positive upward and $\eta_{5}(t)$ positive bow down, as shown in Fig.1. The notations and directions are chosen to be consistent with (Troesch, 1992; Troesch and Falzarano, 1993). $\eta_{3}(t)$ and $\eta_{5}(t)$ can be expressed as follows, respectively:

$$
\begin{aligned}
& \eta_{3}(t)=z(t)-z_{0}, \\
& \eta_{5}(t)=-\left(\tau(t)-\tau_{0}\right)
\end{aligned}
$$

where $\tau(t)$ and $z(t)$ are the effective trim angle and the effective vertical distance of CG from the water level of the craft in motion, respectively.

For the vertical-plane motion of the planing craft, it is generally accepted that the heave/pitch motion can be decoupled from the surge motion for small trim angles (Martin, 1978a,b). This is the case focused on in this paper, and consequently, only heave/pitch motions will be considered.

By adding the forces induced by the transom flap to the form used in (Troesch, 1992; Troesch and Falzarano, 1993), the motion equation of the planing vessel with a controllable transom flap running in the calm water can be written as follows:

$$
A \ddot{\eta}+B \dot{\eta}=F^{R}+F^{F}
$$

where

$$
\begin{aligned}
& \eta=\left[\begin{array}{l}
\eta_{3} \\
\eta_{5}
\end{array}\right], \quad F^{R}=\left[\begin{array}{c}
F_{3}^{R} \\
F_{5}^{R}
\end{array}\right], \quad F^{F}=\left[\begin{array}{c}
F_{3}^{F} \\
F_{5}^{F}
\end{array}\right], \\
& A=\left[\begin{array}{cc}
m+a_{33} & a_{35} \\
a_{53} & I_{55}+a_{55}
\end{array}\right], \quad B=\left[\begin{array}{ll}
b_{33} & b_{35} \\
b_{53} & b_{55}
\end{array}\right],
\end{aligned}
$$

$m$ is the vessel mass and $I_{55}$ the pitch moment of inertia about CG. $a_{i j}$ and $b_{i j}, i, j=3,5$ are the added mass and damping coefficients, respectively. $F_{3}^{R}$ and $F_{5}^{R}$ are the heave and pitch restoring forces, respectively. $F_{3}^{F}$ and $F_{5}^{F}$ are the forces induced by the transom flap in heave and pitch direction, respectively. 
To obtain a model of the planing vessel, those coefficients and forces need to be determined. In our work, $A$ and $B$ are determined based on experimental results of (Troesch, 1992), and $F^{R}$ and $F^{F}$ are calculated using Savitsky's method (1964, 1976).

\section{Added Mass and Damping Coefficients}

Experiments have shown that the added mass, $a_{i j}$, and damping coefficients, $b_{i j}$, for prismatic planing vessels are nonlinear functions of the motion amplitude and frequency (Troesch, 1992). However, compared to the nonlinearities of the restoring forces which will be discussed later, the effects of nonlinearities in $a_{i j}$ and $b_{i j}$ on the craft's motion are small (Troesch and Falzarano, 1993). Therefore, $A$ and $B$ are assumed to be constant at a given forward speed and running attitude. Their values are extrapolated from the experimental results in (Troesch, 1992), depending upon the speed, the equilibrium trim angle and mean wetted length beam ratio.

\section{Restoring Forces}

The forces acting on the planing hull with a transom flap are shown in Fig.2, where $N$ is the water pressure acting normal to the bottom, $T$ the thrust force, $D_{f}$ the frictional drag, $F$ the hydrodynamic force acting on the transom flap, $\varepsilon$ the inclination of the thrust relative to the keel, $l_{p}$ the longitudinal distance of the center of pressure measured from the transom, $a$ the distance between $D_{f}$ and CG, $f$ the distance between $T$ and CG, $\delta$ the deflection of the transom flap, and $g$ the gravity acceleration.

From Fig.2, the restoring forces can be expressed as follows:

$$
\begin{aligned}
F_{3}^{R} & =N \cos \tau+T \sin (\tau+\epsilon)-D_{f} \sin \tau-m g \\
F_{5}^{R} & =D_{f} a-N\left(l_{p}-l_{c g}\right)-T f \\
\tau(t) & =\tau_{0}-\eta_{5}(t) .
\end{aligned}
$$

Consider the simpler case studied in (Savitsky, 1964) where the thrust and the frictional drag pass through CG, i.e. $a=f=0$. To simplify the model, it is also assumed that $\varepsilon=0$, and the sine terms in

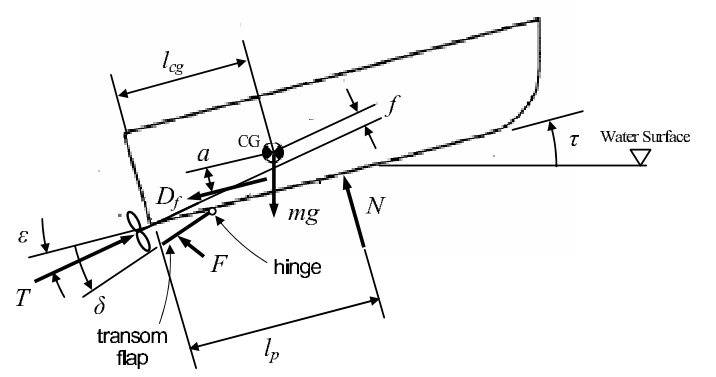

Fig. 2. Forces acting on the planing hull with a transom flap the right hand side of (4) are neglected for small trim angles. Hence, the restoring forces become:

$$
\begin{aligned}
& F_{3}^{R}=N \cos \left(\tau_{0}-\eta_{5}\right)-m g, \\
& F_{5}^{R}=-N\left(l_{p}-l_{c g}\right) .
\end{aligned}
$$

As mentioned in (Troesch, 1992), it is supposed that the effects of the acceleration and velocity of the craft's motion on the hydrodynamic forces have been captured in terms of added mass and damping coefficients in the left hand side of (3). Therefore, only those components as functions of the craft's displacement are considered to determine $F^{R}$.

Savitsky (1964) gave empirical formulas to calculate the restoring forces as functions of the effective mean wetted length-beam ratio, $\lambda$, and the effective trim angle, $\tau$. The involved formulas are listed below:

$$
\begin{aligned}
C_{L_{0}} & =\tau^{1.1}\left(0.0120 \lambda^{0.5}+\frac{0.0055 \lambda^{2.5}}{C_{v}^{2}}\right), \\
C_{L_{\beta}} & =C_{L_{0}}-0.0065 \beta C_{L_{0}}^{0.6}, \\
N & =0.5 \rho V^{2} B^{2} C_{L_{\beta}} \cos \tau \\
l_{p} & =\lambda B\left(0.75-\frac{1}{5.21 \frac{C_{v}^{2}}{\lambda^{2}}+2.39}\right)
\end{aligned}
$$

where $C_{v}=V / \sqrt{g B}$ is the forward speed coefficient, $V$ the forward speed, $B$ the beam length, $C_{L_{0}}$ lift coefficient for a zero deadrise surface, $C_{L_{\beta}}$ lift coefficient for surface with constant deadrise of $\beta$, and $\rho$ water density.

To express the restoring forces as explicit functions of craft displacements, the following relation developed in (Troesch, 1992) is adopted to describe $\lambda$ as a function of $\left(z_{0}, \tau_{0} ; \eta_{3}, \eta_{5}\right)$ :

$\lambda(t)=\frac{1}{B}\left[l_{c g}+\frac{v_{c g}}{\tan \left(\tau_{0}-\eta_{5}(t)\right)}-\frac{z_{0}+\eta_{3}(t)}{\sin \left(\tau_{0}-\eta_{5}(t)\right)}\right]$

where $v_{c g}$ is the vertical distance of CG from the keel.

Given the speed, $V$, the equilibrium running attitude, $\left(z_{0}, \tau_{0}\right)$, and the motion displacement, $\left(\eta_{3}(t), \eta_{5}(t)\right)$, the restoring forces, $F^{R}(t)$, can be obtained by (7)-(13).

\section{Forces By Controllable Transom Flap}

Savitsky and Brown (1976) provided empirical formulas to calculate the forces induced by the transom flap as linear functions of the flap deflection, $\delta$, which is viewed as the control input to the system. The flap lift, $F_{3}^{F}$, and the flap moment about the boat $\mathrm{CG}, F_{5}^{F}$, can be determined by (14) and (15), respectively:

$$
\begin{aligned}
& F_{3}^{F}=d_{3} \delta:=0.023 L_{F} B \sigma \rho V^{2} \delta, \\
& F_{5}^{F}=d_{5} \delta:=d_{3}\left[0.6 B+L_{F}(1-\sigma)\right] \delta
\end{aligned}
$$


where $d_{3}, d_{5}$ are constant coefficients, $L_{F}$ the flap chord length, and $\sigma$ the flap span-beam ratio. $B$, $\rho$ and $V$ are defined as in (9)-(12).

\section{Nonlinear Model}

To summarize, the motion equation of the highspeed planing vessel with a controllable transom flap running in the calm water becomes:

$$
A \ddot{\eta}+B \dot{\eta}=F^{R}\left(z_{0}, \tau_{0} ; \eta\right)+F^{F}(\delta)
$$

where $F^{R}\left(z_{0}, \tau_{0} ; \eta\right)$ is determined by (7)-(13), and $F^{F}(\delta)$ by $(14)-(15)$.

By defining the state vector $x=\left[x_{1}, x_{2}, x_{3}, x_{4}\right]^{T}=$ $\left[\eta_{3}, \eta_{5}, \dot{\eta}_{3}, \dot{\eta}_{5}\right]^{T}$, the motion equation can be transformed to the state-space form as follows:

$$
\dot{x}=f\left(z_{0}, \tau_{0} ; x\right)+b \delta
$$

where

$$
\begin{aligned}
f\left(z_{0}, \tau_{0} ; x\right) & =\left[\begin{array}{cc}
0_{2 \times 2} & I_{2 \times 2} \\
0_{2 \times 2} & -A^{-1} B
\end{array}\right] x+\left[\begin{array}{c}
0_{2 \times 1} \\
A^{-1} F^{R}\left(z_{0}, \tau_{0} ; x\right)
\end{array}\right], \\
b & =\left[\begin{array}{c}
0_{2 \times 1} \\
A^{-1}\left[\begin{array}{l}
d_{3} \\
d_{5}
\end{array}\right]
\end{array}\right] .
\end{aligned}
$$

In general, the restoring forces, $F^{R}$, are nonlinear functions of the motion displacement, $\left(\eta_{3}, \eta_{5}\right)$. An example of $F^{R}$ is illustrated in Fig.2 of (Troesch and Falzarano, 1993). Equation (17) provides a nonlinear model, and will be used for control system design and analysis in the following sections.

\section{MOTION CHARACTERISTICS WITH STATIC TRANSOM FLAP DEFLECTIONS}

Fig. 3 shows an illustrative simulation of heave/pitch motion of the planing hull, where porpoising can be clearly observed. Due to the nonlinear nature of the restoring force in (17), setting the transom flap at different static deflection positions will not only shift the equilibrium running attitude, $\left(z_{0}, \tau_{0}\right)$, but also change the motion response of the planing vessel around the equilibrium. Effects of the preset static deflection of the transom flap on the heave/pitch motion of the planing vessel is analyzed in this section.

\section{Equilibrium Running Attitude}

The equilibrium running attitude of the planing craft, $\left(z_{0}, \tau_{0}\right)$, can be determined by setting $\dot{x}=0$ and $\delta=\delta_{0}=$ const. in (17). The planing hull studied in (Troesch, 1992) is used here, with $l c g / B$ being maintained at 1.95 and $C_{\Delta}$ at 1.47. A fullspan transom flap with the chord length of $0.1 B$ is used to control the craft's motion.

Fig. 4 shows the equilibrium running attitude of the planing craft at different $C_{v}$ and $\delta_{0}$. As Savitsky's method is applicable for trim angles greater
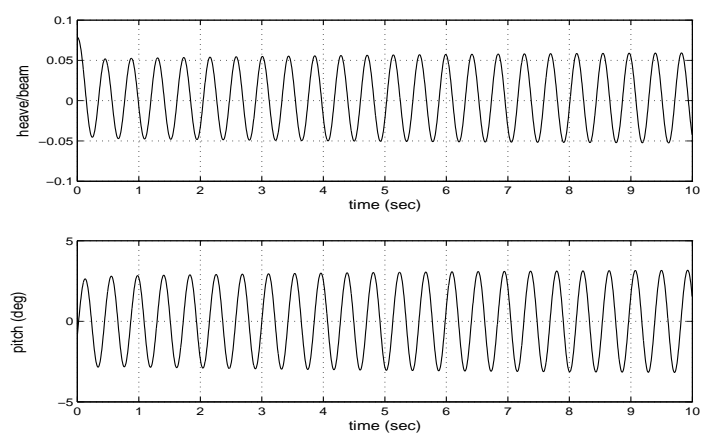

Fig. 3. Heave/pitch motion of the planing vessel when $C_{v}=5.1$ and $\delta=0$.
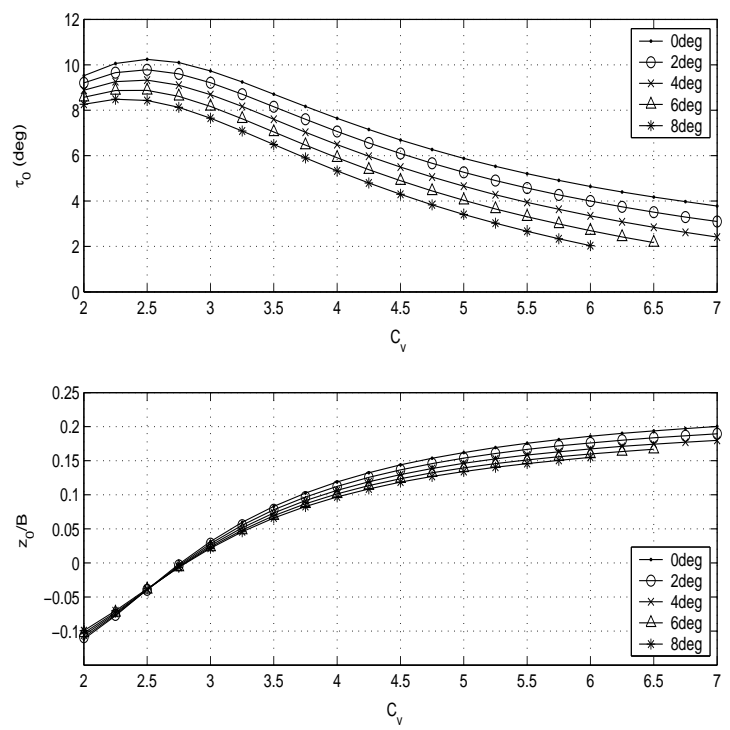

Fig. 4. Equilibrium running attitude

than 2 deg (Savitsky, 1964), results with $\tau_{0}<2 d e g$ are discarded.

As $\delta_{0}$ increases, the trim angle, $\tau_{0}$, decreases at a given forward speed. Larger $\delta_{0}$ increases $z_{0}$ at lower speeds while decreasing $z_{0}$ at higher speeds, but the sensitivity is rather small.

Given $\delta_{0}$, as $C_{v}$ increases, the trim angle, $\tau_{0}$, increases before it decreases at higher speeds. A peak of $\tau_{0}$ appears between $C_{v}=2$ and 3 . The increase of $z_{0}$ as $C_{v}$ increases suggests stronger planing effect at higher forward speeds. The trend of the equilibrium running attitude in Fig. 4 can be verified by the experimental results shown in (Katayama et al., 2000).

The equilibrium running attitude obtained here is expected to be close to the actual planing craft running in the calm water. In (Troesch and Falzarano, 1993), it is assumed that there exists sufficient mechanism to maintain the boat at any attitude. The equilibrium running attitude is given a priori in their analysis. In towing tank experiments, this assumption may be achieved with proper towing mechanisms. In practice, however, the planing hull, when free in the open water, has 


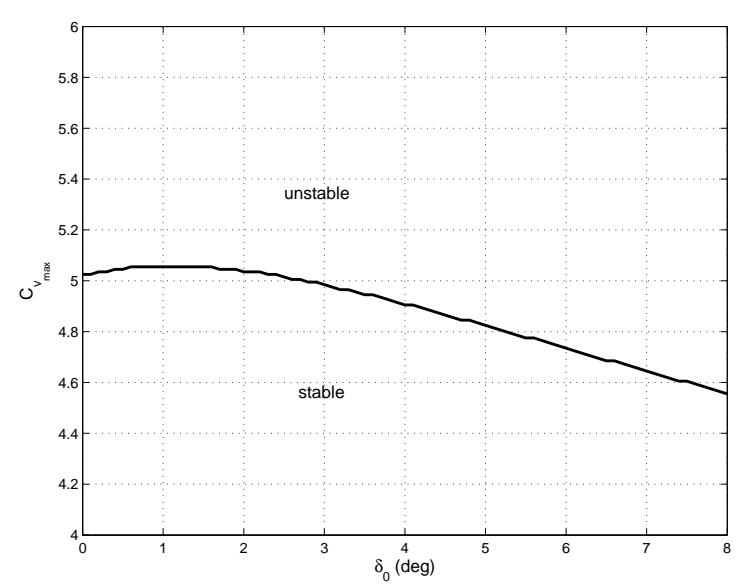

Fig. 5. Maximum speed coefficient where the stability of the planing vessel can maintain.

no mechanism to maintain arbitrary equilibrium running attitude, even with the controllable transom flap. In our work, no extra external mechanism is assumed to obtain a prescribed equilibrium condition. The equilibrium running attitude is calculated based on the forces induced by the boat motion and the transom flap themselves.

\section{Motion Characteristics}

Fig.5 shows the maximum forward speed coefficient, $C_{v_{\max }}$, that the planing hull can maintain without inducing porpoising, for different static deflections of the transom flap. Although a small flap deflection can increase the maximum stable speed by a small increment in Fig.5 (for example, $\delta_{0}=1 \mathrm{deg}$ increases $C_{v_{\max }}$ from 5.02 to $5.05)$, larger deflections reduce the stable operating speed range of the boat. Setting $\delta_{0}=8 \mathrm{deg}$ lowers $C_{v_{\max }}$ down to 4.55 . For speeds with $C_{v}>$ 5.06 , the static transom flap is unable to stabilize the heave/pitch motion of the vessel. Therefore, as far as the vertical-plane motion stability is concerned, the static transom flap actually contributes very little to improve the performance of the planing vessel, except that it reduces the amplitude of the porpoising in some cases, as observed in our simulations. In fact, we could conclude that it even aggravates the problem by inducing the onset of porpoising at lower speed. ${ }^{2}$ To extend the maximum stable operating speed range without redesigning the hull, dynamic feedback stabilization through the controllable transom flap is pursued in next section.

Fig. 6 shows the steady-state motion of the planing vessel in the state space. By simulating the model from different initial perturbations, the boat's steady-state motions result in the same pattern

2 While the negative effect of the preset static transom flap on the vessel's stability is verified for the boat considered in this paper, we should point out that, in general, these effects are problem and design specific, and different design parameters could lead to different conclusions.
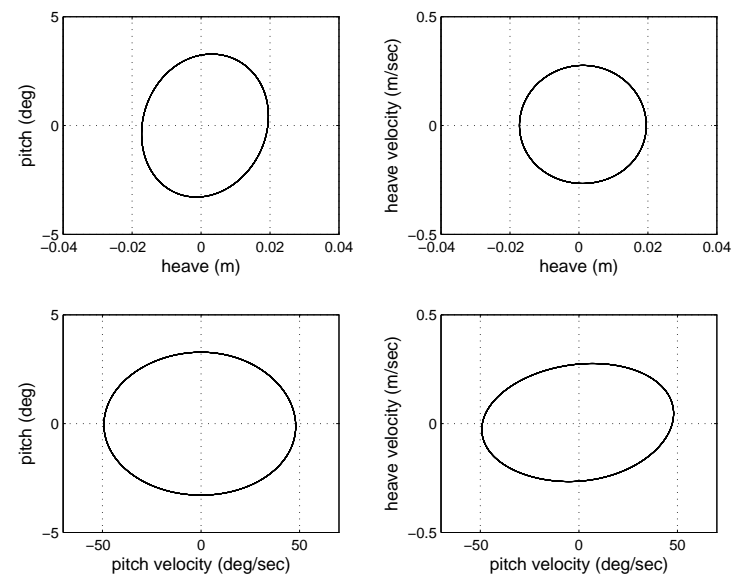

Fig. 6. Steady-state motion trajectory in the state space. $C_{v}=5.1$ and $\delta_{0}=0$.

as shown in Fig.6, which suggests that it is initial condition independent, and the motion of porpoising under this operating condition is basically a stable limit cycle.

It should be noted that Savitsky's method is applicable within certain conditions, such as $\lambda \leq 4$ and $2^{\circ} \leq \tau \leq 15^{\circ}$ (Savitsky, 1964). In our simulation, these limits are often violated and therefore the results have to be discarded. To extend the results to larger motions, it is important to modify the empirical relations and expand the applicable range. This will be a topic of future research.

\section{FEEDBACK STABILIZATION}

Analysis in Section 3 shows that porpoising cannot be eliminated by the preset static transom flap deflection at high speeds. Large deflections may even induce porpoising at lower speeds. A feedback stabilizing controller, based on LQR method, is then designed in this section to enhance the stability of the planing craft at high speeds.

Fig.7 shows the control mechanism of the system, where $K$ is the feedback control gain to be designed. The control input of the system, $\delta$, is decomposed into two parts: $\delta=\delta_{0}+u_{\delta}$, where $\delta_{0}$ is the preset nominal deflection that determines the equilibrium running attitude of the planing craft, and $u_{\delta}$ is the relative deflection about $\delta_{0}$ as a feedback control input. The closed-loop system is described as follows:

$$
\dot{x}=f\left(z_{0}, \tau_{0} ; x\right)+b \delta_{0}-b K x
$$

Local asymptotical stability of the closed-loop system can be achieved by performing LQR design on the linearized model of the nonlinear system described in (18). Two simulation results of the heave/pitch response and the feedback control effort of the closed-loop system are shown in Fig.8, where a rather simple cost function, $J=$ 


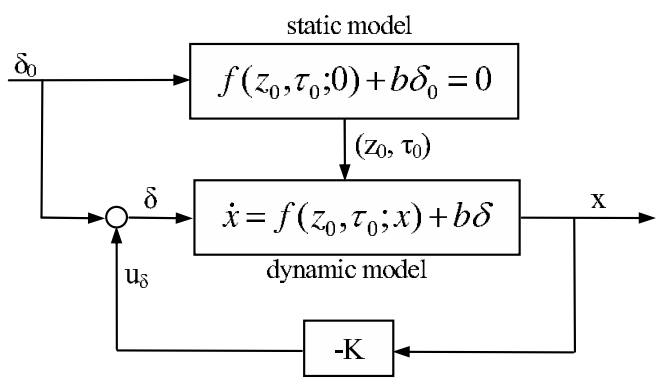

Fig. 7. Control loop of the system
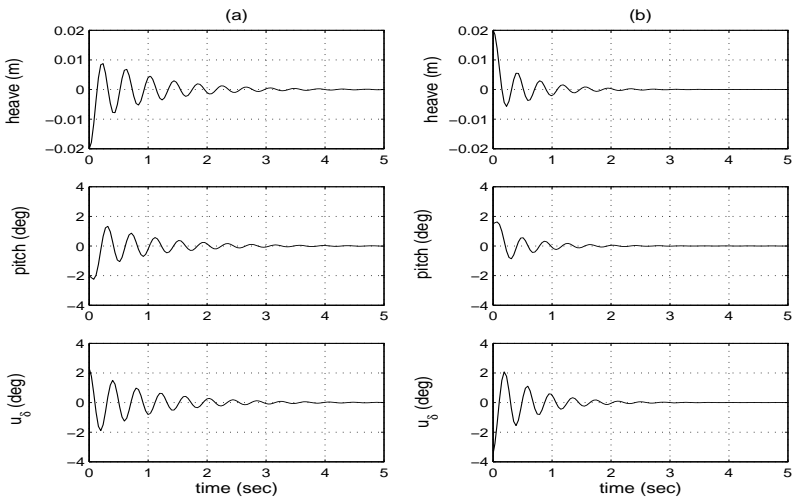

Fig. 8. Heave/pitch response and feedback control input of the closed-loop system. $\delta_{0}=$ 3 deg, $\rho=1000$. (a) $C_{v}=5.5, K=$ $[5.47,2.34,77.73,21.16]$; (b) $C_{v}=6.0, K=$ $[8.10,3.55,127.43,34.18]$.

$\int_{0}^{\infty}\left[\rho \eta_{5}^{2}(t)+u_{\delta}^{2}(t)\right] d t$, is used and $\rho \geq 0$ is the weighting factor to shape the closed-loop system performance.

It is necessary to investigate the nonlinearity in the system to assure the validity of the linear design and analysis results derived from the above approach. Setting the feedforward nominal deflection of the transom flap, $\delta_{0}$, at different position may affect the system performance and feedback control effort, which leads to a study on the combined feedforward/feedback controller design. The effects of the actuator limits, such as amplitude/rate limits, on the control authority are also to be analyzed.

\section{CONCLUSION}

A control-oriented nonlinear model is developed in this paper for the prismatic high-speed planing vessel with a controllable transom flap, to study the effectiveness of vertical-plane motion control of planing boats by controllable appendages. The effects of the static transom flap deflection on the equilibrium running attitude and motion stability are investigated. An LQR controller is also designed to maintain the boat stability by eliminating porpoising at high speeds.
The modeling and analysis work in this paper provide a baseline for future studies on advanced control development for high speed planing vessels, such as performance improvement of highspeed planing vessels running in waves by the controllable transom flap.

\section{ACKNOWLEDGEMENTS}

The authors would like to express their appreciations to Prof. Troesch and Dr. Savander in the Department of Naval Architecture and Marine Engineering of the University of Michigan for their comments and suggestions on the modeling work.

\section{REFERENCES}

Blount, D.L. and L.T. Codega (1992). Dynamic stability of planing boats. Marine Technology 29(1), 4-12.

De la Cruz, J.M., J. Aranda, J.M. Giron-Sierra, F. Velasco, S. Esteban, J.M. Diaz and B. de Andres-Toro (2004). Improving the comfort of a fast ferry. IEEE Control Systems Magazine 24(2), 47-60.

Hicks, J.D., A.W. Troesch and C. Jiang (1995). Simulation and nonlinear dynamics analysis of planing hulls. Journal of Offshore Mechanics and Arctic Engineering 117, 38-45.

Iketa, Y. and T. Katayama (2000). Stability of high speed craft. In: Contemporary Ideas on Ship Stability (D. Vassalos et al., Ed.). pp. 401-409. ELSEVIER Science Ltd.

Katayama, T., T. Hinami and Y. Ikeda (2000). Longitudinal motion of a super high-speed planing craft in regular head waves. In: Proc. of the 4th Osaka Colloquium on Seakeeping Performance of Ships. pp. 214-220.

Martin, M. (1978a). Theoretical determination of porpoising instability of high-speed planing boats. Journal of Ship Research 22(1), 32-53.

Martin, M. (1978b). Theoretical prediction of motions of high-speed planing boats in waves. Journal of Ship Research 22(3), 140-169.

Savitsky, D. (1964). Hydrodynamic design of planing hulls. Marine Technology 1(1), 71-95.

Savitsky, D. and P.W. Brown (1976). Procedures for hydrodynamic evaluation of planing hulls in smooth and rough water. Marine Technology 13(4), 381-400.

Troesch, A.W. (1992). On the hydrodynamics of vertically oscillating planing hulls. Journal of Ship Research 36(4), 317-331.

Troesch, A.W. and J.M. Falzarano (1993). Modern nonlinear dynamical analysis of vertical plane motion of planing hulls. Journal of Ship Research 37(3), 189-199. 